\title{
Research on the Development of Local Normal Universities Based on the Strategy of "Double First-Class" Construction
}

\author{
Xiaotao Lu \\ College of Education Science, Gannan Normal University, Ganzhou, Jiangxi, China \\ Email: LJY19933@126.com
}

How to cite this paper: Lu, X. T. (2019). Research on the Development of Local Normal Universities Based on the Strategy of "Double First-Class" Construction. Creative Education, 10, 1339-1356.

https://doi.org/10.4236/ce.2019.107100

Received: May 31, 2019

Accepted: July 3, 2019

Published: July 5, 2019

Copyright $\odot 2019$ by author(s) and Scientific Research Publishing Inc. This work is licensed under the Creative Commons Attribution International License (CC BY 4.0).

http://creativecommons.org/licenses/by/4.0/

\begin{abstract}
"Double first-class" is the grand strategy of the country to build a powerful country in higher education, which has been paid more and more extensive attention by the academic circle and even the whole society. In this process, the internal structure and external environment of the development of local normal universities also face bran-new opportunities and challenges. The research holds that the orientation of running a school, discipline construction, teaching staff construction, funds for running schools and other aspects are the main challenges faced by local normal universities. But at the same time in top-level policy innovation, direction of differential development, talent flow mechanism improvement, and special fund connection and other opportunities to obtain a rare opportunity. On this basis, the study puts forward four orientations: Highlighting the role of comprehensive normal universities, focusing on the construction of down to earth discipline, paying attention to application-oriented school-running orientation and enhancing the substantive effect of dialogue international, so as to provide optional strategies for the development of local normal universities.
\end{abstract}

\section{Keywords}

Double First-Class, Local Normal University, Challenges, Opportunities, Choose

\section{Introduction}

On October 24, 2015 and January 24, 2017, "Overall Plan for Promoting the 
Construction of World-Class Universities and Disciplines" (Hereinafter referred to as "Overall Plan") (State Council of the People's Republic of China, 2015) and "Implementation Measures for Comprehensively Promoting the Construction of World-class Universities and Disciplines (Interim)" (Hereinafter referred to as "Implementation Measures") (The Ministry of Education of the People's Republic of China [MOE], 2017a) were released respectively, which opened a new journey of higher education reform and development guided by the "double first-class" strategic concept. The "double first-class" construction implements the basic principles of government-led, multi-stakeholder participation, total control, and dynamic screening to select universities for construction. And the problems of identity-specific, lack of competition, cross-repetition and class solidification of the " 211 " and " 985 " engineering colleges have been solved, which means that the path of higher education development in the "double first-class" construction will be re-planned.

In October 2017, the Communist Party of China will speed up the construction of the "double first-class" into the "Report of the 19th National Congress", which fully reflects the great importance and determination of the Party Central Committee to the construction of a strong country in higher education. At the same time, the construction of "double first-class" has brought severe challenges to the development of local colleges and universities. The competition for talents has become more intense, and the access to resources has become more marginal and the construction environment has become more difficult (Tan \& Wang, 2017). However, the object of study in this paper is the local normal university, that is provincial higher normal colleges and universities which belong to local higher normal colleges and universities, as the main body of teacher education development in our country power, how to seize the opportunity, docking "double first-class" construction, to promote the teachers' education quality, to add strength to the construction of China's higher education power, there is an urgent need to think deeply. This paper is divided into six chapters. Chapter one is the introduction. The second chapter is literature review. The third chapter mainly analyzes the challenges faced by the development of local normal universities under the construction of "double first-class". The fourth chapter mainly points out the opportunities for the development of local normal universities under the construction of "double first-class". Chapter five mainly puts forward the selection strategy of the development of local normal universities under the construction of "double first-class". Chapter six makes a general survey of the whole paper, and puts forward the shortcomings of this research. On this basis, it puts forward the research suggestions of local normal universities.

\section{Literature Review}

From the perspective of China's domestic situation, since the mid-1990s, China has carried out systematic and planned reform and exploration in the field of higher education. The concept of "Project 211" was put forward in 1993. The 
concept of "Project 985" was put forward in 1998.

In 2011, the "2011 Collaborative Innovation" center was proposed, aiming to deepen the reform of higher education system and mechanism, release college self-running school, human resources and other innovative vitality, and to impact the world's first-class universities as the prospect. Overall, the construction of " 211 ", " 985 " projects and the " 2011 Plan" which made an important contribution to concentrate advantage education and teaching resources, key breakthroughs, improve the overall level of China's higher education in some extent, improve the international influence and competitiveness of China's higher education. In addition, it has also made an important contribution to lay a solid foundation for strengthening the country's core competitiveness, and the sustained and healthy development of national economy and society. However, from its development process and operating system mechanism also gradually exposed obvious drawbacks and limitations. In 2015, the "double first-class" construction was put forward, and Chinese higher education entered a new era and a new journey. Relevant research results also focus on the following aspects: First, the background combing of the construction of "double first-class". Wang, H. C., a scholar, systematically sorted out the major changes in China's higher education since the opium war, explained the development origin of the "double first-class" construction from the perspective of history, and elaborated in detail the status quo of China's contemporary economy and international status, and the development of higher education itself is the reason for promoting the construction of "double first-class" (Wang, 2016). Scholar Xiong, B. Q. pointed out that the implementation of " 211 " and " 985 " projects has indeed promoted the development of higher education, but with the gradual progress of the project, problems such as identity solidification, repeat cross and lack of competition have become increasingly obvious, and the goal of "double first-class" construction is to eliminate these disadvantages (Xiong, 2016). The second is the interpretation of the connotation of "double first-class" discipline construction. Scholar Pan, J. said that the key point of "double first-class" construction is discipline, according to the principle of correlation and complementary between disciplines, the boundary between dominant discipline and basic discipline, auxiliary discipline and marginal discipline should be broken to form an ecological system of discipline groups, which has a good impetus to the construction of "double first-class" (Pan, 2016). The third is the discussion in the construction of "double first-class" on the impact of discipline construction. Cai, Z. M. \& Wu, C. P. and other scholars affirmed the "double first-class" construction. They believe that the biggest benefit of the "double first-class" construction is that it can open their horizons and enable universities to cross a single national threshold and position their visions at three dimensions include local, national and global; in addition, the "double first-class" construction also provides a policy opportunity for universities to break down identity barriers, introduce free competition mechanisms, and avoid resource duplication and waste (Cai, Wu, \& Yang, 2016). 
Hou, X. S. believes that "double first-class" construction can further optimize the strategic positioning of the school's development, clarify the phased goals, broaden funding channels, plan key disciplines and cultivate innovative talents (Hou, 2016).

From the perspective of the development of international higher education, the field of higher education is rapidly developing in internationalization, marketization and informatization, the competition of higher education in the global is increasingly fierce, the allocation of school-running resources is also gradually going globalization, and the international mobility of students and scholars is accelerating. This international higher education development situation urgently requires our country higher education realization leap development, establishes a batch of high-level universities and the high-level discipline. What is a world-class university? There is currently no generally accepted definition. Philip G. Altbach believes that a school can be called a first-class university if it has sufficient funds, free academic atmosphere, complete teaching facilities, orderly management and excellent research (Altbach, 2004). Scholars Niland, Khoon et al. believe that world-class universities have characteristics different from other ordinary universities, such as academic freedom, management autonomy, perfect equipment, abundant resources, optimization of teachers and students, scientific research excellence and so on (Liu, 2009: p. 6). How to evaluate world-class universities? As early as 1983, "US News and World Report" evaluated and ranked American universities in seven aspects: Peer review, student quality, faculty resources, graduation and renewal rate, alumni donation, graduation rate and financial resources. The Canadian University Rankings published in "Macleans Newsweek" in 1992 included six indicators: student profile, teacher resource status, financial status, classroom situation, university reputation, and library (Lusy, 2003). How to build a world-class university? Moroccan education economist Jamil Salmi made a discussion in "World Class University: Challenges and Ways". First of all, it should be made clear that researchers are exploring what risks and costs the education mode in groping will bring to universities, and then to play the role of government, other participants and school strategic measures (Salmi, 2009). Akiyoshi Yonezawa, a professor at the University of Tokyo, believes that efforts should be made to resolve the contradiction between internationalization and localization of higher education and focus on building a number of world-class universities.

Through the literature review on the background, research status, development way and other aspects of building world-class universities in China's domestic, the paper preliminary present the development prospect of building world-class universities in China. Through the combing of the world's world-class university conceptual \& feature, evaluation criteria, construction path other aspects, not only can clearly know what kind of university can be called a world-class university. At the same time, it provides reflection for how can China's local normal universities break through the construction of "double first-class" and develop for normal universities with Chinese characteristics. 


\section{Challenges Faced by the Development of Local Normal Universities under the "Double First-Class" Construction}

\subsection{The Contradiction between "Existing Positioning" and "Time Trend" in School Running}

School-running orientation is the definition of category and type, level and goal of a school. It is the overall and fundamental work of school development and also the foundation of school construction and development together (Zhao, 2016). In short, it is the leading route of the development of colleges and universities. At present, most local normal universities in China mainly oriented to basic education and train teachers for local basic education. However, under the background of internationalization, marketization and informationization of higher education, higher normal education is also facing challenges. For example, the international vision of teacher training in local normal universities is insufficient, academic level is not strong, information teaching ability is weak, etc. Especially the proposal of "double first-class" construction in China, how local normal universities serve the needs of local basic education and shock world-class universities and first-class disciplines, that is, on the basis of "existing positioning" (service basic education needs), in line with the "time trend" of "double first-class" construction, re-examine and answer "What university to run, how to run a university", and "How to train teachers, how to improve the quality of teacher training, so that teacher education can reach world-class level" is an unavoidable problem in the development of local normal universities in the new era.

\subsection{The Proportion of "Pedagogical Nature" and "Non-Pedagogical Nature" in Discipline Construction Is Unbalanced}

The discipline is the lifeblood of colleges and universities, the barometer of the development level of colleges and universities, and also the backbone of the construction of "double first-class" at the same time. At present, after a series of reforms, transformations and developments, local normal universities have initially formed a prosperous situation in which the disciplines are complete and comprehensive. However, the discipline is thin, the platform is not high, and confusions such as the lack of high-end academic leaders still exists. At present, there are 181 normal colleges in China (People's Network, 2017a). But only 10 of the "double first-class" colleges and universities (Beijing Normal University, East China Normal University, Capital Normal University, Northeast Normal University, Nanjing Normal University, Central China Normal University, South China Normal University, Hunan Normal University, Southwest University (old name: Southwest Normal University), Shaanxi Normal University) were included in this scope (The Ministry of Education of the People's Republic of China $[\mathrm{MOE}], 2017 \mathrm{~b})$. Among them are 6 ministerial level normal universities and 4 provincial level normal universities. However, most of the selected subjects are 
non-normal-type subjects, and there are very few teacher-type subjects. This reflects that the normal-type discipline construction is not only weak, but also deviates from the scope of normal education. And from the side, it reflects the marginal situation of the local normal school normal-type discipline in the radiation of higher education resources. Therefore, in order to obtain the second round of "double-first-class" disciplines, local normal universities will certainly focus on non-normal disciplines development (especially advanced, sophisticated, cutting edge disciplines), which will inevitably lead to the unbalance between "normal" and "non-normal" disciplines construction.

\subsection{The "Talent Introduction" and "Talent Outflow" of Teacher Team Construction Still Need to Be Reconciled}

First-class universities need first-class subjects, and first-class subjects need first-class teachers (Zhou \& Wu, 2016). It can be seen that first-class teachers play a key role in the construction of "first-class disciplines" and "first-class universities". Therefore, in order to occupy a certain position in the construction of "double first-class", local normal universities should introduce high-end talents, optimize the faculty structure, and at the same time improve the endogenous mechanism of talent management, in order to prevent the possibility of their own high-end talents being "poached" (talent outflow). The reason lies in the contingency of the policy, which leads to the ecological imbalance between the original talent team in the university and the imported talent team under the "double first-class" construction. In addition, due to the limited teaching conditions, school running level, resource allocation and policy attraction of local normal universities, under the guarantee of the daily operation of the school, it is difficult to make a high investment in talent introduction, and the existing teachers also cannot be quickly put in place, making local normal universities in the dilemma of talent introduction.

\subsection{The "Input" and "Expenditure" of School Running Funds Are in Urgent Need of Overall Planning}

Undoubtedly, the construction of "double first-class" requires a certain degree of financial support. However, since the 1990s, China has focused on creating two projects in the field of higher education, such as the "211" project and the "985" project. Since then, the educational finance investment has been more inclined to key institutions (such as Tsinghua University, Peking University, Beijing Normal University, East China Normal University and other Ministry of Education deploy comprehensive universities). In addition, the investment in key national scientific research projects and funds is superior to other ordinary local colleges and universities. Taking 2012 as an example, the source pattern of funding for central regular universities in 2012 was government financial allocation (65.2\%), government use for education tax and fee (0.02\%), school-run industrial social service $(0.42 \%)$, and business income (27.2\%). Social donations (1.14\%), others (5.9\%); local-level regular universities funding source pattern are 
government financial allocation (54.1\%), government use for education tax and fee $(2.04 \%)$, school-run industrial social services $(0.01 \%)$, and business income (38.4\%), social donations $(0.03 \%)$, others $(5.3 \%)$ ( Ma, 2014). Thus it can be seen that there is an imbalance phenomenon in the terms of government financial allocation. Thus it can be seen that the government has an imbalance phenomenon in the terms of financial allocation. Universities affiliated to the ministry of education have obvious advantages over local institutions of higher learning in terms of fund acquisition. Per student education fund is of course higher than that of local institutions of higher learning, so the educational resources of schools are much superior. However, most local normal universities are subordinate to the provinces where they are located, and limited by the local social and economic development, the school does not have sufficient funds. Although in the past decade or so, part of the problem has been solved through a series of measures such as transformation of scientific research achievements, social collection of funds, and university-enterprise cooperation, but funds of "input nature" are still important issues that restrict the development of schools. Coupled with the special nature of the professional courses of the local normal university, it is difficult to achieve short-term "dominant" high benefits, which determines that its own "hematopoietic" function is not strong. In addition, the problems of low utilization rate of funds and irregular use of funds are also the reasons for the imbalance between "investment" and "expenditure" of local normal universities. For example, more expenditure is spent on daily administrative affairs and meetings, and less investment on talent motivation, teaching motivation, stimulation for scientific research, student motivation, cultural motivation and teaching and scientific research materials, which are demand factors closely related to discipline construction and school development (Chen \& Zhao, 2017).

\subsection{The Reality of "Local" and "International" of Contribution Is Insufficient}

Contribution degree is an important criterion in the selection of "double first-class". At present, local normal universities are still confronted with the objective reality of low transformation rate of scientific research achievements, insignificant contribution degree and small international influence, etc. The reasons are as follows: First, it is difficult for local normal universities to produce high-level scientific research results due to factors such as local conditions for running schools, level of economic development, low discipline platform and weak key disciplines. Second, transformation mechanism of scientific research achievements is not complete. The local normal university based on multiple considerations weakens their own motivation for scientific research achievements transformation, and at the same time, they also lack the enthusiasm to actively seek the combination of industry, learning and research, and are unable to promote local economic and social development. As a result, there is a bad cycle of "Low conversion rate-Insufficient service capacity-Insufficient funding", and its "local nature" contribution degree is also reduced accordingly. In addi- 
tion, the cultivation of teachers for local basic education is the focus or inherent presupposition of the development of local normal universities, it is difficult for the influence and contribution degree to quickly reach the "international" level or influence in the short term, and this is also the short slab and insufficient reality that local normal universities have entered into "double first-class".

\section{Opportunities for the Development of Local Normal Universities under the "Double First-Class" Construction}

\subsection{Top-Level Policy Innovation Provides Development Opportunities for Local Normal Universities}

The "exclusiveness" restriction of the "211/985" engineering policy, artificially dividing colleges and universities into "three-six-nine" and so on, directly or indirectly exploited the opportunities for other universities to participate in competition, and annihilated the vitality and motivation of the development of other universities. To this end, in June 2016, the Ministry of Education of China terminated the policy documents related to the "211/985" project and replaced it with the world's "first-class universities" and "first-class disciplines" as the strategic goals of higher education development policies ( $\mathrm{Xu}, 2018)$. As the "Overall Plan" puts forward, innovative financial support methods adopt an open competition mechanism, and stimulate a series of measures such as endogenous and developmental forces in colleges and universities. It can be seen that the top-level policy innovation of "double first-class" construction makes the development goal of higher education change from "key universities" to "all colleges and universities" development change. Especially for local normal universities with distinctive features, their own dominant disciplines and featured disciplines will shift from "special" to "fine" for creating "first-class", which provides policy support to achieve forward-looking and leap-forward development, further stimulated its school-running vitality and development momentum. As in March 2017, during the "First Meeting of the 13th National Committee of the Chinese People's Political Consultative Conference" and "First Session of the Thirteenth National People's Congress of the People's Republic of China" period, the minister of education of China Chen, B. S. pointed out: "Double first-class" construction is an overall consideration, on the same platform, face to all universities, all disciplines, equality treat, cannot build "first-class universities", but can build "first-class disciplines" (China Education News Network, 2017).

\subsection{The Direction of Differential Development Broadens the Living Space for Local Normal Universities}

For a long time, China's higher education pays attention to the development of large and comprehensive, but ignores the connotative development of precision and specialization. To this end, the state started from the "first-class university" and "first-class disciplines" to carry on the "differential" development design. As shown in "Overall Plan", the discipline construction was pointed to "the world-class rank or the front rank", and the top-academic and international in- 
fluence of discipline construction in higher education institutions was emphasized, with emphasis on building distinctive university. From this point of view, the construction of "double first-class" leads the comprehensive universities, especially comprehensive universities participating in the teacher education system to the top-academic and research universities. And it has reserved a wider living space for local normal universities in the field of application and the field of teacher education characteristic. (For example, in terms of comprehensive universities, Tsinghua University will further promote the "double first-class" construction and strive to become a world-class university. And the Peking University also strives to become a world-class university. In terms of comprehensive normal university, Beijing Normal University has further defined its orientation of building "a world-class university with Chinese characteristics that is comprehensive, research-oriented and teacher education leadership". East China Normal University has further defined itself as a world-renowned high-level university with distinctive features and prominent advantages. In terms of local normal universities, Gannan Normal University has always adhered to the traditions of running a school of "Based on the red land to run a school, use Soviet area spirit to educate people, serve the revitalization of Soviet area and being the spiritual successor of the Soviet area", and actively serving the local basic education and economic and social development. Anqing Normal University has always been striving to build itself into a local application-oriented high-level university with distinctive characteristics by relying on abundant local cultural resources and unique geographical advantages.) Under such circumstances, local normal universities should take "first-class" disciplines as the standard and select a few advantageous disciplines for "first-class" discipline construction. Most disciplines are faced with the application type and teacher education characteristics, returning to the main business of the normal and reconstructing the living space. It not only supports the strategic needs of the strong higher education country, but also enhances the contribution degree of serving local economic and social development.

\subsection{The Improvement of Talent Flow Mechanism Provides Guarantee for Local Normal Universities to Attract and Retain Talents}

The promulgation of "Implementation Measures" also means that the competition among universities and colleges becomes increasingly fierce, especially the competition for high-level talents. To this end, on January 25, 2017, "Notice of the General Office of the Ministry of Education on Adhering to the Correct Orientation and Promoting the Rational and Orderly Flow of High-level Talents in Colleges and Universities" (Hereinafter referred to as: "Notice") requirements: Colleges and universities should not use high salaries and high treatments to dig up talents (General Office of the Ministry of Education, 2017), side proof "double first-class" in the construction of national colleges and universities "talent wars" has blew the horn of the march. In addition, the "Notice" also clearly 
pointed out: Adhering to the correct orientation of talent flow, adhering to equality and voluntariness, the principles of procedure specification, improving the internal income distribution system, coordinating and handle the relationship between talent introduction and training, and reasonably determining the remuneration and salary treatment of high-level talents. To some extent, this has standardized the order of talent competition in colleges and universities nationwide, created a loose environment for talent flow, positively guided the rational and orderly flow of talents, released the vitality of talents, and guided the value orientation of talent competition. At the same time, it also provides direction guidance and policy guarantee for local normal universities to deepen the reform of personnel system, introduce high-level talents and stabilize internal talents.

\subsection{Special Fund Provides an Explicit Impetus for the Development of Local Normal Universities}

Generally speaking, the closer the interaction between universities and the government is, the better the development of universities and vice versa will be. However, the long-term emphasis on economic development as the central and efficiency-oriented development orientation has made it difficult for local normal universities to produce "dominant" high benefits due to the special nature of the profession. And it also leads to the government's interaction with them is not close, it is manifested by insufficient substantive support (such as fund investment). "Implementation Measures" clearly stated that local colleges and universities selected for "double first-class" construction, local governments should formulate implementation plans and coordinate all arrangements and funds, and the central government will guide them through special support for local university development funds. It is to a certain extent, highlights the local government in the construction of "double first-class" main position, and contribution degree of local normal university in basic education, the influence of serving local economic and social development as well as the background of characteristic subject, makes the local government to have a new understanding of it, to enhance the "interaction" between each other, to strengthen the substantial support (e.g., favorable policies, special funds, etc.), for the local normal university for the next round of the "double first-class" provides the dominant sources of power.

\subsection{Characteristic Discourse Enhanced the Teacher-Confident of Local Normal Universities Development}

Generally speaking, the texts in "Overall Plan" and "Implementation Measures" all highlight the discourse inclination of "Chinese characteristics", such as "Evaluation of disciplines with Chinese characteristics", "Chinese manner", "Chinese style", "Unique and High-Level Universities" and other policy text discourse. It can be seen from this that the "double first-class" construction is not only a "follow-up" development based on world-class universities and first-class disciplines and foreign third-party evaluations, but take the core road 
with "Chinese characteristics, world first class". In short, it is a "world-class university and first-class discipline" with socialist characteristics with Chinese characteristics. In addition, general secretary Xi, J. P. also pointed out that under the national conditions of socialism with Chinese characteristics, we should run socialist colleges and universities with Chinese characteristics well and follow our own path of higher education development (Guangming Daily, 2017). The development history of normal education in China over the past hundred years is not only a history of development, but also a history of characteristics. In this process, has formed a group to have the strong characteristic the normal university (For example, Beijing Normal University is a key university directly under the administration of the ministry of education. It is a famous institution of higher learning with the main features of teacher education, educational science, basic subjects of arts and sciences, among which characteristic specialty include special education, Chinese language and literature, etc. Huazhong Normal University is a key comprehensive Normal University with teacher education distinctive characteristics under the ministry of education. It is also an important base for the national training of teachers in primary and secondary schools and institutions of higher learning among which characteristic specialty include pedagogy, etc.). The era appeal of "double first-class" construction and the discourse expression of Chinese characteristics for the local normal university to strengthen the characteristics of teacher education, added its due normal confidence.

\section{The Choice of the Development of Local Normal Universities under the "Double First-Class" Construction}

\subsection{Clarify the Development Objective of the Construction and Highlight the Role of "Comprehensive Normal University"}

The author believes that there are three tendencies for the development goals of local normal universities: Comprehensive normal universities as a reference, comprehensive universities as a pursuit, and internationally renowned teacher education institutions as a reference. Here's a brief description of comprehensive universities and comprehensive normal universities. The so-called "comprehensive universities" mean universities with complete range disciplines, abundant resources for running schools and overall level high, aiming to cultivate high-level and versatile talent (Wang, Zong, \& Liu, 2017). In comparison, "comprehensive normal universities" means universities with a relatively complete category of disciplines, which highlight the characteristics of teacher education or other characteristics and focus on the university that trains teachers for basic education.

However, at this stage, problems such as the weakening of the status of teacher education and the decline in the quality of teachers have emerged. For example, some normal universities not only attend to trifles and neglect the essentials but also blindly copied comprehensive university standards; a large number of additional non-normal category professional, compressed normal category profes- 
sional; emphasis is laid on "academic" strong disciplines but neglect "normal" disciplines; keen to the school name change of eliminating the word "normal", eager to transform the "comprehensive university" and other objective phenomena. Especially for a long time, China's normal education is inclined to the training of pedagogy, psychology and professional knowledge, but neglects to cultivate students' academic ability. In fact, the reason is that it is limited in its understanding of the attributes, uniqueness and subject status of its comprehensive normal university. For normal majors, it is both academic and normal, the unification and integration of academic and normal, which is the uniqueness. In addition, in 1999, "Several Opinions on the Layout and Structural Adjustment of Normal Colleges and Universities" clearly put forward: Take normal colleges and universities as the main body, adhere to the independent establishment of the main role of normal colleges and universities. In January 2018, for the first time in the name of the Party Central Committee and the State Council, the "Opinions on Comprehensively Deepening the Reform of the Teacher Team Construction in the New Era" was published, and the extreme importance of teachers was discussed from a strategic height and overall level. In March 2018, the "Teacher Education Revitalization Action Plan (2018-2022)" specifically proposed the construction of the "Teacher Education" secondary discipline, and promoted the development of teacher education from the perspective of discipline construction. From this point of view, the state attaches great importance to and supports the development of normal colleges. Based on this, in the construction of "double first-class", local normal universities should not only learn from and learn from the comprehensive universities, but also pay more attention to the unique value, significance and subject status of their own existence, adhere to the orientation of connotative development and strive to become comprehensive normal universities.

\subsection{Rationally Evaluate the Value Orientation of the Discipline and Pay Attention to the Construction of "Down-to-Earth" Discipline}

Discipline is the key to the development of local normal universities. The so-called "climbing the high ladder" discipline is to take the first-class as the standard, aim at the international frontier, major inventions and discoveries, and lead the academic development. In short, it is a high-grade, precision and advanced discipline. The "down-to-earth" discipline is a discipline that focuses on practical applications and can solve the actual needs of the region's economy, society, and culture. Under the "double first-class" construction, the local normal university must have the courage to "climbing the high ladder" and even more have a "down-to-earth" pragmatic. On the one hand, a few advantageous disciplines should follow the development direction of "climbing the high ladder" and meet the national major bidding subjects and strategic needs. On the other hand, most disciplines should take the development direction of "down-to-earth" and take the mission to serve the basic education and local 
economic and social development.

To be specific, first of all, to cultivate marketable talent of all kinds at all levels for local economic and social development. To do this well, the key is to "match the discipline construction with local demand", and the core is to constantly optimize the discipline structure. Such as national education policy, take the comprehensive practice course as a compulsory course of foundation education, and should need professional teachers to teach, and most of the local normal university has not yet made professional addition, lead to the basic education has demand, but the normal university has no corresponding professional talents, this is a local normal university discipline construction need deep thinking. Second of all, the professional service think tank of local normal universities should be established to precisely connect the problems of local economic and social development. Firstly, according to the idea of "problem-oriented and task-driven", the professional service think tank should be established based on the practical problems in local economy, science and technology, industry and culture; give full play to the advantages of local normal universities in scientific research talents, patented technologies and scientific research achievements; promoting the transformation of scientific research achievements and technology transfer; solve the shortcoming of local industrial renewal and upgrading; promote the speed and quality of local economic development. Secondly, at present, the proposal of the national rural revitalization strategy and the construction of beautiful villages are just around the corner. Local normal universities should rely on various discipline resources, contact the government, actively integrate into regional development, carry out multi-disciplinary and multi-perspective research and demonstration, to provide scientific, forward-looking and targeted research reports for local governments in the construction of beautiful villages; helping to realize the rural revitalization strategy and the construction of beautiful countryside, to reflect the local university's own strength and to obtain the recognition of local governments and all sectors of society.

\subsection{Align with the Times Demands of Social Development, Focus on the School Orientation of "Application-Oriented"}

It is generally believed that higher education is closely related to knowledge production. In knowledge society, knowledge production mode I to knowledge production mode II transformation, leading to profound changes in the relationship between talent supply and social demand, both need a certain amount of research personnel, and need more quantity of applied talents (Yin, 2015). What are "research" universities and "application-oriented" universities? This is more of a broad description of the policy text and the academic community has not yet formed a unified conclusion. From the perspective of disciplines, research universities correspond to basic disciplines, that is, science for science's sake, and the core is "discovery knowledge". Application-oriented universities correspond to applied discipline, that is, focus on the application of knowledge, the core of which is "study for the sake of application" (Lu, Chen, \& Zhang, 
2015: p. 430), emphasizing the characteristics of the practical orientation and applicability (Wang \& Wang, 2018).

In 2015, the three ministries jointly issued the "Guidance on Guiding Some Local Ordinary Undergraduate Colleges and Universities to Transform into Application-Oriented Universities", making it clear that "application-oriented universities" which in China will become an important direction for the transformation and development of local undergraduate colleges and universities. Generally speaking, the development orientation of most local normal universities in China is application-oriented, but in the process of practical teaching, they often follow the traditional academic training mode, which is inconsistent with the standards of application-oriented talent training in many aspects, leading to the output of talents is still in the situation of strong theory and weak practice. Therefore, under the construction of "double first-class", local normal universities should pay more attention to the construction of applied disciplines in the wave of application-oriented transformation.

To be specific, the first is to set up the concept of application-oriented teaching. Concepts are the forerunner of actions. If the curriculum concept, teaching concept and teachers' concept do not change, no matter how many incentive policies are also invalid, and the transformation development will be suspended. Therefore, local normal universities should do a top-level design, clarify the direction and objectives of applied-oriented teaching reform, take the application-oriented talent training as the core, take the curriculum teaching reform as a breakthrough, and stimulate the enthusiasm of teacher reform. And strengthen theoretical teaching and practical teaching seamless integration, promote the profound transformation of the application-oriented teaching concept. The second is to make an application-oriented discipline construction plan. The first thing for local normal universities to do is to seek the point of convergence with their own discipline construction in the practical fields such as local economy and industry, and find the direction point and anastomosis point of convergence of discipline construction plans. Only then can local normal universities clearly define the key directions and goals of the construction and formulate the applied discipline system planning systematically and comprehensively, to improve the synergy between ourselves and enterprises and local economic and social development, and promote the orderly landing of applied disciplines. Third, strengthen the construction of applied subject teachers. At present, most of the local normal universities are traditional academic talents, with profound theoretical knowledge and weak practical skills, while applied talent training requires more professional teachers with practical skills. Therefore, local normal universities should start with the "double teacher double energy type" teacher, reform the personnel assessment and employment system, build and develop a flexible employment mechanism, and on campus to support and build a "double teacher double energy type" teacher team. Fourth, vigorously carry out applied scientific research. From a regional perspective, serving local economic, social, and cultural development is an important responsibility of local normal universities. Ap- 
plication-oriented science research in local normal universities should not only pay attention to the hot spots of the frontiers of the disciplines, but also pay more attention to the practical effects and deep integration with local industries. When conducting research in a discipline, researchers should pay attention to the rate of scientific research conversion, the degree of promotion, and the value of application. They should not only pay attention to the knowledge problems of the discipline itself, but also more refine the topics from the actual needs of local industries, and strengthen the government, universities, and enterprises in-depth cooperation to build a trinity collaborative innovation mechanism. From the perspective of basic education, strengthen the in-depth cooperation between the government, universities, primary and secondary schools, promote the deep integration of educational theories and educational practices, lead the professional growth of primary and secondary school teachers, and promote the quality of basic education.

\subsection{Stick to the Characteristic Road of Focusing on Domestic and Enhance the Substantive Effect of "International Dialogue"}

"Focus on domestic" and "dialogue international" are different platforms or directions that are interrelated in the strategic development positioning of colleges and universities. The so-called "focus on domestic" is to foothold in domestic, around national conditions, start from China, out of a road of higher education with Chinese style and Chinese manner. The so-called "dialogue international" is to have a big vision, a big role, and dare to learn, communicate and compete in a high-level international platform (People's Network, 2017b). Therefore, local normal universities should not only focus on their own pedagogical characteristics, pays attention to national conditions, keeps a watchful eye on regional education issues and economic and social development issues, but also have the vision and courage to engage in international dialogue, break the limitations of regional attributes and expand its ecological niche.

In the "Implementation Measures", the internationalization degree and international discourse power and influence of colleges and universities are taken as important indicators. To this end, local normal universities can promote internationalization through the following aspects. To be specific, first, adhere to the development concept of an international perspective. Cultivating talents with international vision, familiar with international rules, and being able to participate in international affairs is not only the appeal of the development of the times, but also the needs of a strong higher education country. At the same time it is also the strategic goal proposed by "National Program for Medium- and Long-Term Education Reform and Development (2010-2020)". And the internationalization of university visits, academic exchanges and teacher-student exchanges is the norm, but only the internationalization of the surface. In the case of local normal universities, it means placing its own reform and development strategy in the context of the world's political and economic macro-changes, examining its own deficiencies in an international perspective, and seeing where 
its gaps are, and how to proceed in the future. Second, build an international platform for collaboration and sharing. The holding of international academic conferences is undoubtedly an important event in the process of internationalization. But when experts and scholars from different nationalities and fields gather together to discuss the frontier of discipline development and lead the development of international economic, social and cultural industries, what is more needed is to further build a mechanism for domestic and international cooperation in scientific research and a mechanism for achievement transformation. So as to promote the in-depth study of the university, the local area and the country issues, to deepen the breadth and depth of international academic exchanges, and to generate substantial achievements. Then it exerts a wide influence in the whole country and even in the world, gains a prominent position and grasps the voice of the industry. Third, it is to create a diversified cultural ecology. In the process of internationalization, different academic views, different educational concepts and different regional cultures have dialogue and integration in this international "melting pot". It is in this context that respecting differences, respecting culture, and understanding education will become indispensable, and the establishment of a diversified cultural ecosystem will become an inevitable trend.

\section{Conclusion}

In a word, under the background of "double first-class" construction strategy, the development of local normal universities faces rare opportunities and potential challenges. After clarifying the internal and external environment, local normal universities urgently need to seek breakthroughs in such aspects as target construction orientation, discipline value orientation, school-running positioning orientation, and characteristic road direction of China's normal education, so as to create a new era of China's normal education development. Although this paper has made some preliminary achievements and pointed out the development direction from the qualitative perspective, there are still some limitations. Especially the lack of detailed quantitative analysis on the input cost, development benefit, discipline evaluation and value evaluation and other aspects of the development of local normal universities.

\section{Conflicts of Interest}

The authors declare no conflicts of interest regarding the publication of this paper.

\section{References}

Altbach, P. G. (2004). Costs and Benefits of World-Class Universities (Qin, W. Z. Trans.). Academe, 90, 20-23. https://doi.org/10.2307/40252583

Cai, Z. M., Wu, C. P., \& Yang, K. K. (2016). The "Double First-Class" Strategy in the Perspective of Globalization and the Choice of Local Colleges and Universities. Chongqing Higher Education Research, 1, 25-32. 
Chen, R. S., \& Zhao, J. X. (2017). Research on the Development of Local Colleges and Universities under the Background of "Double First-Class" Construction. Education and Teaching Research, 8, 39-40.

China Education News Network (2017). Chen, Baosheng: Double First-rate Selection without "Lifelong Tenure".

http://www.jyb.cn/zcg/xwy/wzxw/201703/t20170312 475664.html

General Office of the Ministry of Education (2017). Notice on "Stick to the Right Orientation to Promoting the Rational and Orderly Flow of High-level Talents in Colleges and Universities".

http://www.moe.gov.cn/SrcSite/A04/s7051/201701/t20170126 295715.html

Guangming Daily (2017). Focusing on the World's Forefront of Science and Technology and Serve Major Strategic Needs.

http://epaper.gmw.cn/gmrb/html/2017-09/12/nw.D110000gmrb 20170912 2-06.htm https://doi.org/10.1016/S0262-1762(18)30052-X

Hou, X. S. (2016). A Brief Analysis of University Development Planning Under the Perspective of Double First-Class Construction. Education Modernization, 8, 243-248.

Liu, N. C. (2009). World-Class Universities: Strategy, Innovation and Reform. Shanghai: Shanghai Jiao Tong University Press.

Lu, X. Z., Chen, W., \& Zhang, W. (2015). Research on the Strategic Management of the Development of Modern Higher Education (the Series of Chinese Education Research). Beijing: Beijing Normal University Press.

Lusy, G. W. (2003). Resources to Higher Education. International Journal of Educational Development, 23, 381-398. https://doi.org/10.1016/S0738-0593(02)00070-6

Ma, Y. Y. (2014). Research on the Improvement of Fundraising Ability of Local Normal Colleges-Taking L Normal University as an Example. Liaoning Normal University.

Ministry of Education, Ministry of Finance, National Development, \& Reform Commission of the People's Republic of China (2017a). Notification of the Issuance of "Implementation Measures for Comprehensively Promoting the Construction of World-Class Universities and Disciplines (Interim)".

http://www.moe.gov.cn/srcsite/A22/moe 843/201701/t20170125 295701.html

Ministry of Education, Ministry of Finance, National Development, \& Reform Commission of the People's Republic of China (2017b). Announcement of the "List of World-Class Universities and First-class Discipline Construction Universities and Construction Disciplines".

http://www.moe.gov.cn/srcsite/A22/moe 843/201709/t20170921 314942.html

Pan, J. (2016). The Connotation and Action Framework of "Double First-Class" Construction. Jiangsu Higher Education, 5, 24-27.

People's Network (2017a). Ministry of Education: During the 13th Five-Year Plan Period, China's 181 Normal Colleges and Universities Absolutely Will Not Change Their Names and Take off Their Hats. http://politics.people.com.cn/n1/2017/0116/c1001-29024881.html

People's Network (2017b). Xi, Jinping Talks about Opening to the Outside World: Dare to Swim in the Boundless Seas of the World Market. http://cpc.people.com.cn/xuexi/n1/2017/0704/c385474-29381645.html

Salmi, J. (2009). The Challenge of Establishing World. Washington DC: World Bank Publications. https://doi.org/10.1596/978-0-8213-7865-6

State Council of the People's Republic of China (2015). Notice on the Publication of the "Overall Plan for Promoting the Construction of World-Class Universities and Discip- 
lines".

http://www.moe.gov.cn/jyb xxgk/moe 1777/moe 1778/201511/t20151105 217823.ht $\underline{\mathrm{ml}}$

Tan, G. X., \& Wang, Z. L. (2017). Situation and Strategy: Discipline Construction of Local Universities under the Background of "Double First-Rate" Strategy. Journal of National Academy of Education Administration, No. 8, 53.

Wang, H. C. (2016). The Focus of "Double First-Class" Construction Lies in Disciplines. Chongqing Higher Education Research, 1, 7-11.

Wang, W. J., \& Wang, H. C. (2018). The Logical Origin and Deepening Path of the Reform of Research-Based Teaching in Colleges and Universities-The Propulsion Framework based on the Transformation of Knowledge Production Mode. Research in Educational Development, 1, 64 .

Wang, Y. L., Zong, X. P., \& Liu, W. P. (2017). The Connotation Research of “Comprehensiveness" in Comprehensive Universities under the Perspective of Undergraduate Teaching. China University Teaching, 3, 67.

Xiong, B. Q. (2016). “Double-First-Class”: China's Construction of World-Class Universities Version 2.0. People's Tribune, 7, 52-54.

Xu, J. (2018). National-Capacity in University Developing: Practical Appeal, Evolutionary Path and Theoretical Review-Based on the Analysis from "Key Universities" to "Double First-Rate". Jiangsu Higher Education, 6, 25.

Yin, N. W. (2015). Transformation of Knowledge Production Modes and Cultivation of Applied Undergraduate Talents. Chongqing Higher Education Research, 2, 22.

Zhao, M. R. (2016). Discourse Analysis of Visions of China's Normal University in the New Century. Teacher Education Research, 1, 84.

Zhou, G. L., \& Wu, J. X. (2016). What is the World First-Class Disciplines? China Higher Education Research, 1, 69. 